\title{
Federalism and individual liberty: a rejoinder
}

\section{Mantzavinos}

Published online: 19 December 2010

(C) Springer Science + Business Media, LLC 2010

In their thoughtful comment of my paper on Federalism and Individual Liberty, Kirchgässner and Schelker (2011) address a series of points which are well-taken and would certainly merit discussion. I would like to make, however, only one general remark addressing the thrust of the argument in their comment which suggests that my analysis is untenable.

Their comment reshapes my discussion on liberty on the basis of the antithesis of rights versus benefits, which I have nowhere used in my paper. Though I have not myself juxtaposed rights with benefits, the authors arbitrarily choose this framework in order to combat my arguments and to reach their preferred conclusion. But this is only their first step. In their second step they proceed further and, again arbitrarily, state that: "Nevertheless, in our everyday life we weight quite often individual liberties against aspects of well-being, individually as well as politically. [...] Thus, it is totally acceptable to consider the problem of individual liberty in the case of federalism from a welfarist point of view" (p. 2). Their whole discussion hinges upon this choice, which distorts my argument. I have myself admitted (when listing the limitations of my analysis in Sect. 9 of my paper) the great difficulty of trying to treat individual liberty as an analytical variable, but at the same time I clearly stress that going the easy way of using utility instead of liberty is not feasible (Mantzavinos 2010, p. 116).

Liberty and welfare, though related, are distinct, and the paper does not take any stance regarding their relationship. Furthermore, it is constructed in such a way that an assumption regarding their relationship is not necessary. In my discussion of the first effect of federalism on individual liberty, I clearly stress that the diversity of institutional arrangements per se enhances the alternatives open to a citizen, and so it is the very existence of a choice set that secures his liberty. That a citizen might then make a choice of a certain alternative with the expectation that it will best

C. Mantzavinos $(\bowtie)$

Witten/Herdecke University, Chair of Economics and Philosophy,

Alfred-Herrhausen-Str. 50, 58448 Witten, Germany

e-mail: mantzavinos@uni-wh.de 
satisfy his desires — as I write in my paper (p. 105) — does not mean, as Kirchgässner and Schelker suggest, that I assume a welfarist point of view or that utility considerations enjoy some kind of primacy. All that matters for securing individual liberty is the existence of alternatives and not how these alternatives are used or the principles according to which choices are made.

In analyzing the second effect of federalism on individual liberty my focus is on how the plurality of authorities exerting discretionary political power affects the decision of a citizen to exit the jurisdiction under which he lives. My analysis of exit costs is offered only in order to illuminate the way that the diversity of institutional rules (which will result from the exertion of political power by a plurality of authorities) can itself hinder the liberty of the individual. To restate my point: "The higher the exit costs for any citizen, the more difficult the decision to change jurisdiction and thus, in effect, the less his individual liberty becomes. The psychological costs of adaptation to a new institutional environment function as an impediment to the individual freedom to choose the jurisdiction under which he wants to live." (p. 110f.) This quotation along with the analysis of the exit costs is not intended as some kind of welfarist analysis. On the contrary, it suggests that the very fact that citizens incur psychological costs because of the diversity of institutional rules, which is due in turn to the plurality of jurisdictions in a federalist system, is indicative of a de facto reduction of their choice set and thus of their liberty. This effect is indirect because it is the result of a whole mechanism at work, but it is not utility that is of concern here. The use of the conceptual apparatus of exit costs and the like is only supposed to help illuminate this mechanism and it can be omitted if it misleads some readers to assume a welfarist point of view. I have restated the argument elsewhere in my paper without using the notion of exit costs, and one can use this description if one prefers (p. 113): "This indirect line of argument concerns the effect institutional diversity has of increasing the degree of difficulty a citizen has to move from one jurisdiction to another. A consequence of this fact, which is an unintended result of a federalist organization of a polity, is a decrease in individual liberty. This effect, which is an indirect one because it is neither designed nor planned by the constitutional designers, causes a diminution of what I have called the Indirect Individual Liberty. It is, in a certain way, a quasi-automatic effect, caused and enhanced by the peculiarity of human nature to adapt well to prevailing institutional settings and thus to find it difficult to re-adapt to new ones."

If one sticks to the definitions of the terms and the explanation of the mechanism provided in the paper, then my analysis remains valid. The reformulation of the problem and the reshaping of the arguments with the help of utility considerations by Kirchgässner and Schelker serve only to distort my argument and in no way affect its validity.

\section{References}

Kirchgässner, G., \& Schelker, M. (2011). Federalism and exit costs. A comment on: C. Mantzavinos, federalism and individual liberty. Constitutional Political Economy. doi: 10.1007/s10602-010-9100-x.

Mantzavinos, C. (2010). Federalism and individual liberty. Constitutional Political Economy, 21(2), $101-118$. 